\title{
The Transduction Channel Filter in Auditory Hair Cells
}

\author{
Anthony J. Ricci, ${ }^{1}$ Helen J. Kennedy, ${ }^{2}$ Andrew C. Crawford, ${ }^{3}$ and Robert Fettiplace ${ }^{2}$ \\ ${ }^{1}$ Center for Neuroscience, Louisiana State University Medical Center, New Orleans, Louisiana 70112, ${ }^{2}$ Department of Physiology, University of Wisconsin \\ Medical School, Madison, Wisconsin 53706, and ${ }^{3}$ Department of Physiology, Cambridge University, Cambridge CB2 3EG, United Kingdom
}

In the first step in auditory transduction, sound-induced vibrations of the stereociliary bundles on the sensory hair cells are converted into electrical signals by opening of mechanotransducer channels. Faithful transduction and hence auditory performance will be limited by the kinetic properties of these channels. We have measured the time course of mechanotransducer currents in turtle and rat auditory hair cells during rapid deflections of the hair bundle. Current activation in the turtle had a time constant that decreased 10-fold with stimulus amplitude to a limiting value of $\sim 50 \mu$ s. Lowering the external $\mathrm{Ca}^{2+}$ concentration slowed both activation and adaptation time constants. Similar effects were seen in hair cells tuned to low and high frequencies, but the overall kinetics was slower in low-frequency cells. In rat outer hair cells, the time courses of both activation and adaptation were at least 10-fold faster. Although activation kinetics was too fast to characterize accurately, the adaptation time constants in the rat, like the turtle, were $\mathrm{Ca}^{2+}$ dependent and faster in hair cells tuned to higher frequencies. The results imply that mechanotransducer channels operate similarly in turtle and rat but are faster in the mammal to accommodate its higher frequency range of hearing. We suggest that the kinetics of channel activation and adaptation imposes a bandpass filter on transduction, with a center frequency matched to the frequencies detected by the hair cell, which may improve the signal-to-noise ratio near threshold.

Key words: calcium; fast adaptation; electrical resonance; mechanosensitive channels; outer hair cells; rat; signal-to-noise ratio; stereociliary bundle

\section{Introduction}

Hair cells of the inner ear are unusual among sensory receptors in the speed of their response, and in the mammalian cochlea, they must generate receptor currents replicating the acoustic waveform at frequencies of tens of kilohertz. Sound stimuli are detected by displacements of the hair-cell stereociliary bundles, stretching interciliary tip links that open mechanotransducer (MET) channels in the stereocilia (Hudspeth, 1989; Fettiplace, 2004). A minimal delay, $<50 \mu$ s between stimulus onset and channel gating, implies a direct mechanical coupling and precludes involvement of diffusible second messengers used in other sensory receptors (Corey and Hudspeth, 1979, 1983). Because of the response speed, it has been difficult to obtain accurate information about the kinetics of transduction because the frequency responses of both stimulation and recording techniques are close to the limit of what is currently achievable. Previous experiments in the frog (Corey and Hudspeth, 1983) and turtle (Crawford et al., 1989) have shown that for a step displacement of the hair bundle, the MET current develops with a submillisecond time constant that decreases with an increase in stimulus amplitude. However, in only one case (Crawford et al., 1989) were record-

Received March 22, 2005; revised June 27, 2005; accepted July 14, 2005.

This work was supported by National Institutes on Deafness and Other Communicative Disorders Grants R01 DC 01362 to R.F. and R01 DC 03896 to A.J.R. We thank Ham Farris for useful comments on this manuscript.

Correspondence should be addressed to Robert Fettiplace, 185 Medical Sciences Building, 1300 University Avenue, Madison, WI 53706. E-mail: fettiplace@physiology.wisc.edu.

H. J. Kennedy's present address: Department of Physiology, School of Medical Sciences, University of Bristol, Bristol BS8 1TD, UK.

DOI:10.1523/JNEUROSCI.1127-05.2005

Copyright $\odot 2005$ Society for Neuroscience $\quad$ 0270-6474/05/257831-09\$15.00/0 ings made on a single hair cell under voltage clamp. In the other, the results were inferred from extracellular transepithelial currents averaged over the saccular epithelium, which had a broader band width but arose from an array of cells that were not patch clamped (Corey and Hudspeth, 1983). Nevertheless, both sets of observations were used to argue that the time course of the current onset reflects the gating kinetics of the MET channel rather than the stimulus delivery. The aim of the present work was to obtain more extensive information about the kinetics of the MET current and to explore whether it depends on the environment or frequency range of the hair cell.

In response to a sustained displacement of the hair bundle, the MET channels open rapidly but then reclose in a process referred to as adaptation. Adaptation reflects the operation of multiple mechanisms with time constants ranging from a fraction of a millisecond to several hundred milliseconds (Eatock, 2000; Fettiplace and Ricci, 2003). Most of these processes are controlled by a change in stereociliary $\mathrm{Ca}^{2+}$ after influx of the ion through MET channels that are highly calcium permeable (Ohmori, 1985; Ricci and Fettiplace, 1998). The speed of fast adaptation and its block only by relatively high concentrations of calcium buffers suggest that $\mathrm{Ca}^{2+}$ acts directly on the channels to modulate their gating (Ricci et al., 1998; Wu et al., 1999). Here, we measured the time course of the MET current in response to hair-bundle deflections using a rapid piezoelectric stimulator. We show that $\mathrm{Ca}^{2+}$ affects the time constant of channel activation as well as adaptation, supporting the idea of a direct interaction of the ion with the channels. Furthermore, we find differences between channel kinetics in auditory hair cells of mammals and nonmam- 
mals, suggesting the MET channel properties are matched to the sound frequencies processed by the hair cell.

\section{Materials and Methods}

Turtle preparation. The preparation and method of hair-cell recording in the intact basilar papilla of the turtle (Trachemys scripta elegans) were similar to those described previously (Ricci and Fettiplace, 1997). Turtles were decapitated, and the cochlea and lagena dissected out using procedures approved by the Animal Care Committee of the University of Wisconsin. The cochlear duct was opened, and the tectorial membrane was removed after digestion in normal saline of the following composition (in $\mathrm{mM}$ ): $125 \mathrm{NaCl}, 4 \mathrm{KCl}, 2.8 \mathrm{CaCl}_{2}, 2.2 \mathrm{MgCl}_{2}, 2 \mathrm{Na}$ pyruvate, 8 glucose, $10 \mathrm{Na}$-HEPES, pH 7.6, containing up to $50 \mu \mathrm{g} \mathrm{mg} / \mathrm{ml}$ of protease (type XXIV; Sigma, St. Louis, MO). The preparation was transferred to a recording chamber on the stage of a Zeiss (Oberkochen, Germany) Axioskop FS microscope and viewed through a $40 \times$ water immersion objective. The bath was perfused with normal saline of the composition given above. The upper surface of the hair-cell epithelium was perfused separately through a $100 \mu \mathrm{m}$ pipette with saline of the following composition (in $\mathrm{mm}$ ): $130 \mathrm{NaCl}, 0.5 \mathrm{KCl}, 2 \mathrm{Na}$ pyruvate, 8 glucose, $10 \mathrm{Na}-$ HEPES, pH 7.6, containing control $(2.8 \mathrm{~mm})$ or reduced $(0.05 \mathrm{~mm})$ $\mathrm{CaCl}_{2}$. The lower $\mathrm{Ca}^{2+}$ concentration of $0.05 \mathrm{~mm}$ is similar to that measured for turtle endolymph (Crawford et al., 1991). Whole-cell currents were recorded at $-80 \mathrm{mV}$ holding potential (and in some experiments at $+80 \mathrm{mV}$ ) with a borosilicate patch electrode attached to an Axopatch $200 \mathrm{~A}$ amplifier with a $50 \mathrm{kHz}$ output filter. The time constant of the recording system was between 15 and $30 \mu$ s after applying up to $70 \%$ series resistance compensation. Patch electrodes were filled with an intracellular solution of the following composition (in $\mathrm{mM}$ ): $125 \mathrm{CsCl}, 3$ $\mathrm{Na}_{2} \mathrm{ATP}, 2 \mathrm{MgCl}_{2}, 1 \mathrm{Cs}_{4}$ BAPTA, 10 Cs-HEPES, pH 7.2. In some experiments, to increase the $\mathrm{Ca}^{2+}$ buffering, the pipette solution contained 10 mM Cs ${ }_{4}$ BAPTA or $3 \mathrm{~mm} \mathrm{Cs}_{4} \mathrm{~F}_{4}$ BAPTA, the $\mathrm{CsCl}$ being reduced to maintain constant osmolarity. Most recordings were made from hair cells in two regions, one at $d=0.25-0.34$ and the other at $d=0.63-0.74$, where $d$ is the fractional distance along the basilar membrane from the lowfrequency end. Based on a frequency map for the turtle cochlea, hair cells at these two positions have characteristic frequencies of $80-100$ and 200-270 Hz, respectively. Mechanotransducer currents were digitized with a Power 1401 at $150 \mathrm{kHz}$ (Cambridge Electronic Design, Cambridge, UK) and analyzed with Cambridge Electronic Design Signal software and with Igor Pro (WaveMetrics, Lake Oswego, OR). Mechanotransducer currents shown are average responses to 10 presentations.

Rat preparation. Mammalian experiments were performed on outer hair cells in the apical and middle turns of the organ of Corti isolated from Sprague Dawley rats between postnatal day 7 (P7) and P10. Animals were killed by decapitation using procedures approved by the Animal Care Committee of the University of Wisconsin. After removing the bone from the apical and middle turns, the stria vascularis was unpeeled, and then, after a $15 \mathrm{~min}$ incubation in saline containing $50 \mu \mathrm{g} / \mathrm{ml}$ of bacterial subtilisin protease (type XXIV; Sigma), the tectorial membrane was removed. The excised apical and middle turns were fixed in the experimental chamber with strands of dental floss and, as with the turtle cochlea, viewed through a $40 \times$ long working distance water-immersion objective on a Zeiss Axioskop FS microscope. The experimental chamber was perfused with artificial perilymph of the following composition (in mM): 154 $\mathrm{NaCl}, 6 \mathrm{KCl}, 1.5 \mathrm{CaCl}_{2}, 2 \mathrm{Na}$-pyruvate, 10 glucose, and $10 \mathrm{Na}$-HEPES, $\mathrm{pH}$ 7.4. The apical surface of the organ of Corti was perfused separately through a $100 \mu \mathrm{m}$ pipette with a perilymph-like solution with normal $\mathrm{CaCl}_{2}(1.5 \mathrm{~mm})$ or reduced $\mathrm{CaCl}_{2}(0.02 \mathrm{~mm})$ having a concentration similar to that in rat endolymph (Bosher and Warren, 1978). The reduced-Ca ${ }^{2+}$ solution was buffered with $4 \mathrm{~mm} 2 \mathrm{~N}-(2-$ hydroxyethyl)ethylenediaminetriacetic acid, and the free $\mathrm{Ca}^{2+}$ concentration in the apical perfusate was verified with a $\mathrm{Ca}^{2+}$ electrode (MI-60; Microelectrodes, Londonderry, $\mathrm{NH}$ ) that had been calibrated in a series of calcium buffer solutions (World Precision Instruments, Sarasota, FL). Borosilicate patch electrodes connected to an Axopatch 200A amplifier were introduced through a small hole in the reticular lamina (Kennedy et al., 2003). Outer hair cells were whole-cell voltage clamped at a holding potential of $-84 \mathrm{mV}$ at room temperature $\left(19-22^{\circ} \mathrm{C}\right)$. Recordings were
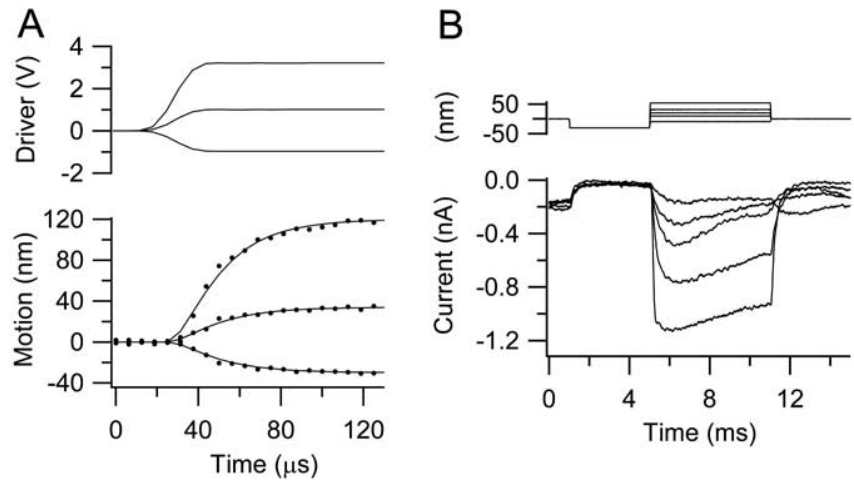

Figure 1. Experimental methods. A, Driving voltages to the piezoelectric actuator for three stimuli are shown above, and the evoked displacements of the probe, determined by projecting its image onto a photodiode pair, are shown below. Driving voltage was filtered with an eightpole Bessel filter at $10 \mathrm{kHz}$, and signals were digitized at $150 \mathrm{kHz}$. Smooth lines are exponential fits to (digitization) points with a time constant of $34 \mu \mathrm{s}$. Note the delay between movement and driving voltage. $\boldsymbol{B}, \mathrm{MET}$ currents were measured for a series of positive test displacements that were preceded by a $4 \mathrm{~ms}$ conditioning negative step that deactivated the channels. Note that $\sim 20 \%$ of the MET current is activated at rest in low $(0.05 \mathrm{~mm}) \mathrm{Ca}^{2+}$.

made from first or second row outer hair cells at the beginning of the apical turn, $\sim 0.8$ of the distance along the basilar membrane from the base, and in the middle turn, 0.5 of the distance from the base. From the place-frequency map in adult rats, the recording site corresponds to characteristic frequencies of $\sim 4$ and $14 \mathrm{kHz}$, respectively (Müller, 1991). Patch pipettes were filled with an intracellular solution of the following composition (in mM): $142 \mathrm{CsCl}, 3.5 \mathrm{MgCl}_{2}, 1$ EGTA, $5 \mathrm{Na}_{2} \mathrm{ATP}, 0.5$ $\mathrm{Na}_{2}$ GTP, and 10 Cs-HEPES, pH 7.2. To minimize limitations imposed by the speed of the recording system, low-resistance $(<2 \mathrm{M} \Omega)$ patch pipettes were used, giving a recording time constant with up to $80 \%$ seriesresistance compensation of between 10 and $20 \mu$ s. The shank of the patch pipette was coated with wax to reduce capacitance. The lag time constant on the Axopatch 200A was set to $8 \mu \mathrm{s}$. Mechanotransducer currents were digitized with a Power 1401 at $200 \mathrm{kHz}$ (Cambridge Electronic Design) and analyzed as for the turtle records. All results are expressed as means $\pm 1 \mathrm{SD}$.

Mechanical stimulation. Hair bundles were deflected by the axial motion of a glass pipette waxed to and driven by a piezoelectric stack actuator (model PA8/12; Piezosystem Jena, Hopedale, MA or model P-802; Physik Instrumente, Karlsruhe, Germany). For measurements in the turtle, the tip of the pipette was fire-polished to $\sim 1 \mu \mathrm{m}$ in diameter, but for the rat it was $\sim 3 \mu \mathrm{m}$ in diameter so as to fit into the $\mathrm{V}$-shaped stereociliary bundle of the outer hair cell. The larger size was essential for driving the entire hair bundle in the mammal. The actuator had a resonant frequency of $50 \mathrm{kHz}$ and was driven with voltage steps that were filtered with an eight-pole Bessel filter set at a frequency $F_{\mathrm{B}}$ of $10-13 \mathrm{kHz}$ (turtle) or $5-10 \mathrm{kHz}$ (rat). This filtering was necessary to remove parasitic oscillations attributable to a lateral resonance of the glass pipette. The time course of motion of each glass probe was calibrated by projecting its image onto a pair of photodiodes as described previously (Crawford and Fettiplace, 1985). The photodiode measuring system had a bandwidth of $40 \mathrm{kHz}$. In response to a voltage step filtered at $F_{\mathrm{B}}$, the mechanical displacement had a $10-90 \%$ rise time of $\sim 0.4 / F_{\mathrm{B}}$. Thus, with the stimulus Bessel filter set at $10 \mathrm{kHz}$, the probe displacement had a rise time of $40 \mu \mathrm{s}$ and was delayed by $\sim 30 \mu$ s relative to the voltage step (Fig. $1 A$ ). During a hair-cell recording, it was not possible to measure the time course of motion of the hair bundle using the photodiode system, because the image was dominated by the glass probe, which had a much higher contrast than the bundle. It was therefore assumed that the bundle faithfully followed the motion of the probe. This assumption seems justified for the following reasons: (1) the probe and stack are much stiffer than the bundle, and, because the probe is placed behind the bundle, it will push the bundle to an new position without restraint; (2) the actual motion of the hair bundle must be at least as fast as the fastest time course of current activation. Because for large stimuli, this is very close to the time course of 
probe motion in free solution, it seems likely that probe and bundle move as one; (3) if the probe were not stuck to the bundle, there might be expected to be a larger lag in the response to the smallest stimulus, which was not observed. Because the bundle motion was not directly measured during a recording, the time course of the stimulus in the figures is represented by the driving voltage to the piezoelectric actuator, delayed by an amount $(30-50 \mu \mathrm{s})$ determined in the calibration of the relevant filter setting. MET currents were measured for a series of positive displacements (toward the kinocilium) that were preceded by a $4 \mathrm{~ms}$ conditioning negative step that deactivated the channels (Fig. $1 B$ ). The use of this experimental paradigm, in which the test pulses are delivered from a starting time where all the channels are closed, simplifies the kinetic analysis for both voltage-dependent (Hodgkin and Huxley, 1952) and mechanosensitive (Corey and Hudspeth, 1983) channels.

\section{Results \\ Calcium dependence of MET channel kinetics in turtle hair cells}

Deflections of the hair bundle elicited inward MET currents that reached a peak in $<0.5 \mathrm{~ms}$ and then declined to a steady level in a process of adaptation. The presence of fast adaptation complicates the analysis of the onset kinetics. As a consequence, the initial analysis was performed on hair cells tuned to low frequencies, in which fast adaptation was less pronounced and slower with a time constant of $2 \mathrm{~ms}$ or more. In this type of cell, the MET current in response to a step deflection of the hair bundle developed with a sigmoidal onset that could be fit with a pair of time constants indicating two kinetic processes for channel activation (Corey and Hudspeth, 1983; Crawford et al., 1989; van Netten and Kros, 2000). One of these was a fast process, invariant with level, with a time constant of $\sim 30 \mu \mathrm{s}$, and the other was a slower process, the time constant of which depended on stimulus level (Fig. 2) (Corey and Hudspeth, 1983; Crawford et al., 1989). The subsequent description will focus on the slower rate-limiting process. For each stimulus level $L$, the onset of the MET current with time $t$ after the start of the displacement step was fitted with a single exponential plus a delay $(\Delta t)$ as follows: $I=I_{\mathrm{O}}[1-\exp$ $\left.\left((\Delta t-t) / \tau_{\text {act }}\right)\right]$, where $I_{\mathrm{O}}(L)$ is the peak current for that stimulus, and $\tau_{\text {act }}(L)$ is the time constant of activation. In six hair cells tuned to low frequencies, the slower principal time constant $\tau_{\text {act }}(L)$ decreased from $\sim 400 \mu$ s for small displacements to 40-60 $\mu$ s for large saturating stimuli. The fastest time constants are likely to be limited by the time course of onset of the stimulus. Nevertheless, the values are within the range of values measured in isolated turtle hair cells in $2.8 \mathrm{~mm}$ extracellular $\mathrm{Ca}^{2+}$ (Crawford et al., 1989).

When the $\mathrm{Ca}^{2+}$ bathing the hair bundle was reduced to 0.05 $\mathrm{mm}$, several aspects of the response altered including an increase in the maximum amplitude of the current and a slowing of the time course of adaptation, as reported previously (Crawford et al., 1991; Ricci et al., 1998). The mean adaptation time constant for six cells increased from $1.8 \pm 0.2 \mathrm{~ms}$ in $2.8 \mathrm{mM} \mathrm{Ca}^{2+}$ to $3.6 \pm$ $0.2 \mathrm{~ms}$ in $0.05 \mathrm{mM} \mathrm{Ca}^{2+}$. In addition, the activation time constant in the same cells changed about twofold in parallel with the adaptation time constant (Fig. 2). The mean activation time constant at the resting position of the hair bundle increased in the six cells from $0.37 \pm 0.03 \mathrm{~ms}$ in $2.8 \mathrm{mM} \mathrm{Ca}^{2+}$ to $0.75 \pm 0.3 \mathrm{~ms}$ in 0.05 $\mathrm{mM} \mathrm{Ca}{ }^{2+}$. The time constant of adaptation was five to seven times that of activation, and it seems unlikely, therefore, that the decline in the current caused by adaptation interfered with the measurements of activation kinetics in these low-frequency hair cells. There was some variability in the $\mathrm{Ca}^{2+}$ effect on the level dependence of the activation time constant. In some cases, the time constants in low and high $\mathrm{Ca}^{2+}$ converged at the highest
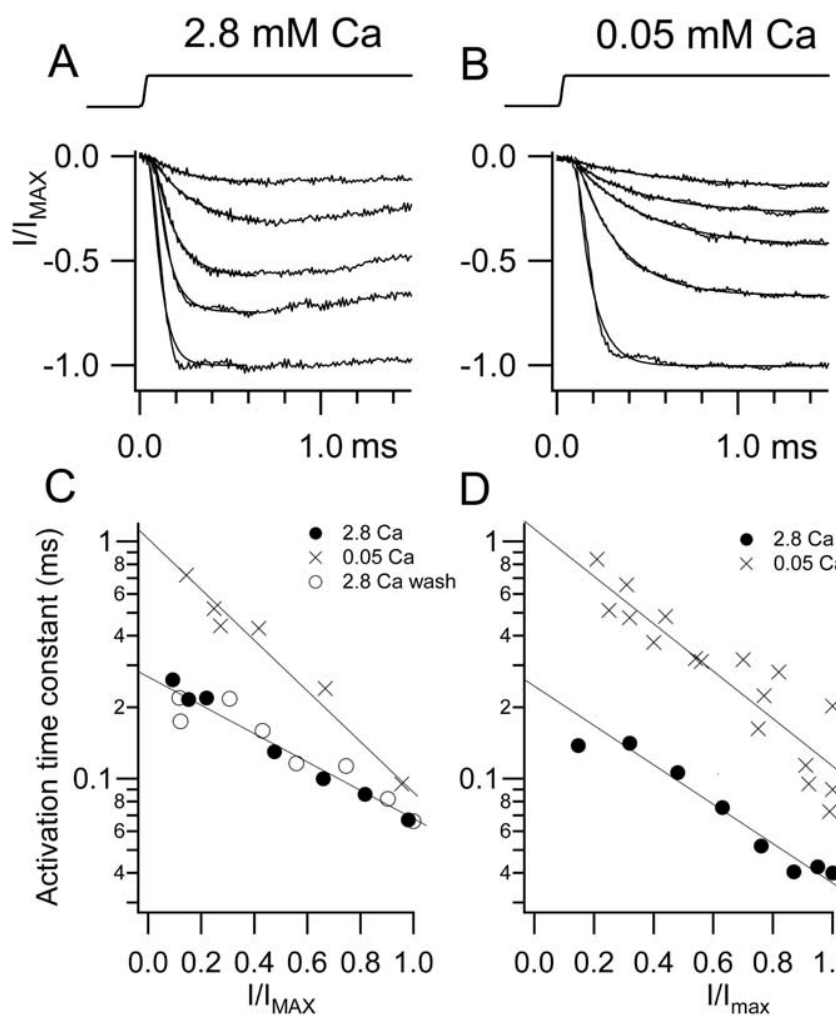

D

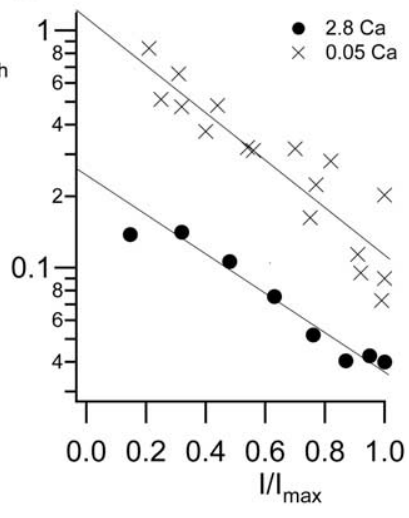

Figure 2. Effects of $\mathrm{Ca}^{2+}$ on activation time constants of MET channel in turtle auditory hair cells. $\boldsymbol{A}$, MET current onsets for increasing amplitudes of hair bundle displacement in $2.8 \mathrm{~mm}$ extracellular $\mathrm{Ca}^{2+}$. In this and the subsequent figure, the time course of the bundle deflection (shown above) is indicated by the time course of the driving voltage delivered to the piezoelectric actuator, delayed by $30 \mu$ s (see Materials and Methods). In all figures, positive bundle displacements are preceded by a negative 4 ms conditioning step to deactivate the channels as in Figure 1, but for simplicity, the displacement is shown relative to that just before the step. The amplitudes of the MET currents have been scaled to a maximum current, $I_{\text {max }}$ of $0.73 \mathrm{nA}$. Single-exponential fits (see Results) have been superimposed on the traces to give a time constant of current activation. The fits begin after a small $(\sim 30 \mu \mathrm{s})$ delay. A low-frequency hair cell $(d=0.35)$ with a holding potential of $-80 \mathrm{mV}$ (same cell as Fig. 1$)$ is shown. $\boldsymbol{B}$, MET current onsets in the same cell for hair bundle displacement in $0.05 \mathrm{~mm}$ extracellular $\mathrm{Ca}^{2+} \cdot I_{\max }=1.10$ nA. $\boldsymbol{C}$, Plots of the time constants obtained from the fits in $\boldsymbol{A}$ and $\boldsymbol{B}$ versus fractional current activated $\left(I / I_{\text {max }}\right)$. Also shown is the return control to $2.8 \mathrm{~mm} \mathrm{Ca}^{2+}$. Lines through points have been extrapolated back to intersect the ordinate. $\boldsymbol{D}$, Activation time constants in another cell showing a kinetic slowing on reducing $\mathrm{Ca}^{2+}$ similar to $C . I_{\max }=0.89 \mathrm{nA}\left(2.8 \mathrm{mMCa}^{2+}\right)$ and 1.5 $\mathrm{nA}\left(0.05 \mathrm{~mm} \mathrm{Ca}^{2+}\right)$.

stimulus levels (Fig. 2C); in other cases, the fits (on a logarithmic scale) remained approximately parallel (Fig. $2 D$ ). The convergence may reflect the fact that even in low $\mathrm{Ca}^{2+}$, the effect of the mechanical stimulus on the opening rate constant of the MET channel becomes dominant. However, the convergence could be an artifact of the kinetics becoming limited by the stimulation and recording time constants.

In contrast to the effect of lowering extracellular $\mathrm{Ca}^{2+}$, depolarization, which might be expected to reduce $\mathrm{Ca}^{2+}$ influx, had no influence on the time constant of activation (Fig. 3). In these experiments, the hair bundle stimulus was superimposed on a 20 ms depolarizing voltage step because the cell deteriorated if held for any length of time at $+80 \mathrm{mV}$. We failed to find any effect of membrane potential on activation kinetics in recordings from six different hair cells. However, in all cases, there was a pronounced slowing of the offset kinetics, as reported previously, an effect shared with wash-in of high intracellular BAPTA concentrations (Crawford et al., 1989). Depolarization to $+80 \mathrm{mV}$ also abolished 
adaptation, as reported previously (Crawford et al. 1989; Ricci et al., 2000)

Fast adaptation is thought to be controlled by changes in stereociliary $\mathrm{Ca}^{2+}$ after influx of the ion through the MET channels. Support for this mechanism comes from the observation that adaptation is slowed by increasing the concentration of a calcium buffer such as BAPTA in the intracellular solution (Ricci and Fettiplace, 1997; Ricci et al., 1998). A similar approach was used to investigate the role of $\mathrm{Ca}^{2+}$ in channel activation. Recordings were made using patch-pipette solutions containing BAPTA at a concentration of $10 \mathrm{~mm}$ instead of the standard $1 \mathrm{~mm}$. Slowing of the activation time course and loss of adaptation occurred as $10 \mathrm{~mm}$ BAPTA solution was washed into the cell (Fig. 4). Thus, the onset time constant of the response to a small displacement step doubled from the time after just gaining electrical access to the cytoplasm to $6 \mathrm{~min}$ from breakthrough. Such slowing was seen in a total of five experiments, in which the time constant of the response measured 1-2 min after breakthrough increased on average 3.3-fold after 6-9 min. In three of the cells, all low frequency, the small signal time constant exceeded $1 \mathrm{~ms}$ after 6 min recording (Fig. 4C), considerably slower than the equivalent results with $1 \mathrm{~mm}$ BAPTA intracellular and $2.8 \mathrm{mM} \mathrm{Ca}^{2+}$ extracellular. Experiments using a low-affinity calcium buffer, $\mathrm{F}_{4}$ BAPTA $(3 \mathrm{~mm})$, which has a calcium dissociation constant of $65 \mu \mathrm{M}$ and reduces or abolishes adaptation (Ricci et al. 1998), also showed a slowing of current activation with wash-in of the buffer (Fig. 4D). The efficacy of $\mathrm{F}_{4}$ BAPTA suggests that the $\mathrm{Ca}^{2+}$ concentration must be high, tens of micromolar, near the site controlling channel activation and adaptation. By comparison, no such slowing of either activation or adaptation kinetics was seen over the same wash-in period when using $1 \mathrm{~mm}$ BAPTA, which has comparable buffering capacity to the endogenous mobile calcium buffer (Tucker and Fettiplace, 1996; Ricci et al., 1998). Nor in those experiments was there evidence of deterioration in the cell, indicated for example by a change in $I_{\max }$, over this period. The effects of increasing intracellular calcium buffering are consistent with the notion that MET channel activation, like adaptation, is sensitive to the level of intracellular $\mathrm{Ca}^{2+}$.

\section{Tonotopic variation in activation time constant in the turtle}

The time constant of fast adaptation has been shown to depend on the distance of a hair cell along the tonotopic axis of the turtle cochlea, cells at higher frequency locations possessing faster adaptation (Ricci et al., 1998, 2003). To search for differences in the activation kinetics between hair cells at different locations, it was necessary to make measurements in low $0.05 \mathrm{mM} \mathrm{Ca}^{2+}$. Adaptation in cells tuned to high frequencies was sufficiently fast in 2.8 $\mathrm{mm}$ extracellular $\mathrm{Ca}^{2+}$ to make it difficult to fit accurately the current onset. However, a comparison was possible in low $\mathrm{Ca}^{2+}$. The rising phase of the current was fit with a single time constant that for hair cells at both locations decreased with level (Fig. 5). Collected results on six low-frequency cells and five highfrequency cells suggested an approximately twofold difference in the activation time constant (Fig. 5C,D), similar to the difference in the adaptation time constant. When the activation time constants were plotted semilogarithmically against the fraction of
B

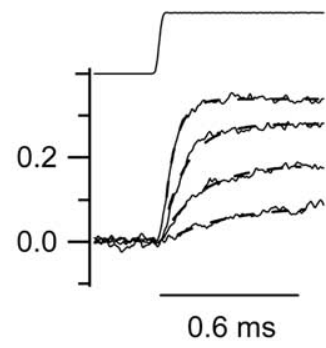

C

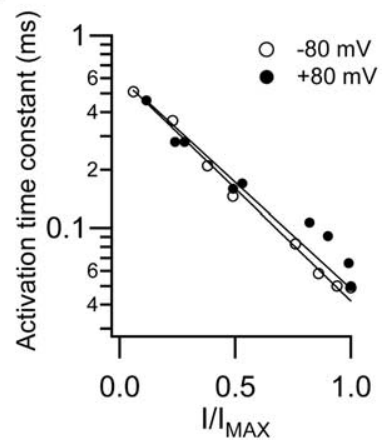

Figure 3. Lack of effect of membrane potential on activation kinetics. $\boldsymbol{A}$, MET current onsets at $-80 \mathrm{mV}$ holding potential. $\boldsymbol{B}$,

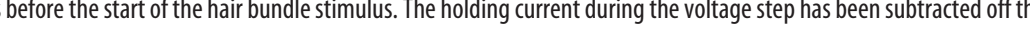
fits in $\boldsymbol{A}$ and $\boldsymbol{B}$, plotted versus fractional current activated $\left(I / I_{\mathrm{max}}\right) \cdot I_{\max }=0.44 \mathrm{nA}(-80 \mathrm{mV})$ and $0.34 \mathrm{nA}(+80 \mathrm{mV})$. The fits to each set of points are virtually identical. A low-frequency hair cell $(d=0.25)$ in $2.8 \mathrm{~mm}$ extracellular $\mathrm{Ca}^{2+}$ is shown.

A

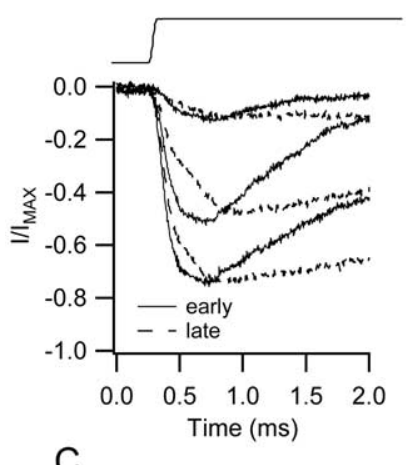

C

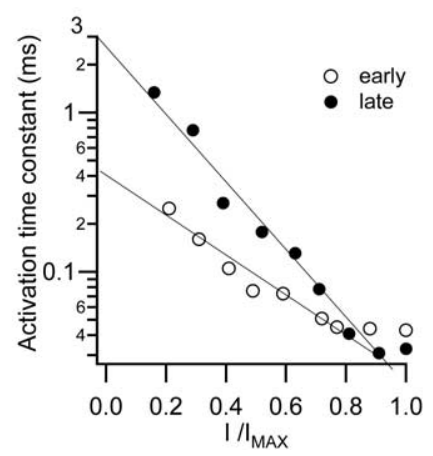

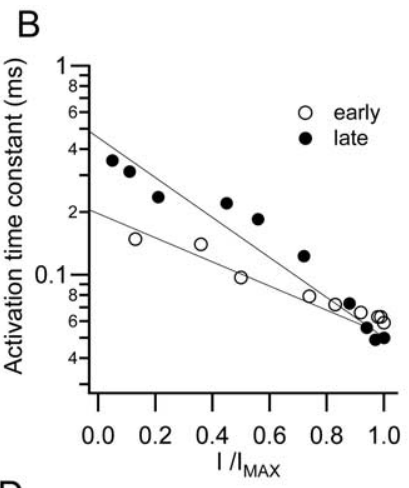

$\mathrm{D}$

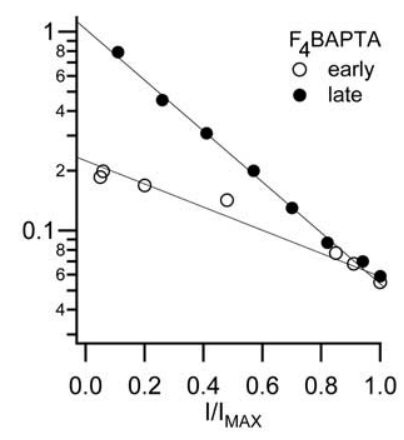

Figure 4. Slowing of MET channel activation kinetics on wash-in of high concentrations of calcium buffer. $\boldsymbol{A}$, Three average traces showing the onsets recorded $1.5 \mathrm{~min}$ (early; continuous lines) and $6 \mathrm{~min}$ (late; dashed lines) after gaining access to the cell interior with patch electrode solution containing $10 \mathrm{~mm}$ BAPTA as the calcium buffer. Note the slowing of the onset and loss of adaptation at later time. $I_{\max }=0.89 \mathrm{nA}$. B. Activation time constants at early and late times plotted against fractional current activated for the cell in $\boldsymbol{A}$. $\boldsymbol{C}$, Activation time constants at 1.4 $\min$ (early) and $8 \mathrm{~min}$ (late) plotted against fractional current activated for a low-frequency cell during wash-in of an intracellular solution containing $10 \mathrm{~mm}$ BAPTA as the calcium buffer. $I_{\max }$ $=0.42 \mathrm{nA}$. D. Activation time constants at $<2 \mathrm{~min}$ (early) and $8 \mathrm{~min}$ (late) plotted against fractional current activated for a low-frequency cell during wash-in of a solution containing 3 mu low-affinity calcium buffer $\mathrm{F}_{4}$ BAPTA. $I_{\max }=0.5 \mathrm{nA}$.

MET current activated, they were well described by a straight line (Fig. 2C,D). Extrapolation of this line back to where it intercepts the ordinate at zero current provided a means of quantifying the results for comparing activation kinetics under different conditions. (It should be noted that the back extrapolation of the fitted 

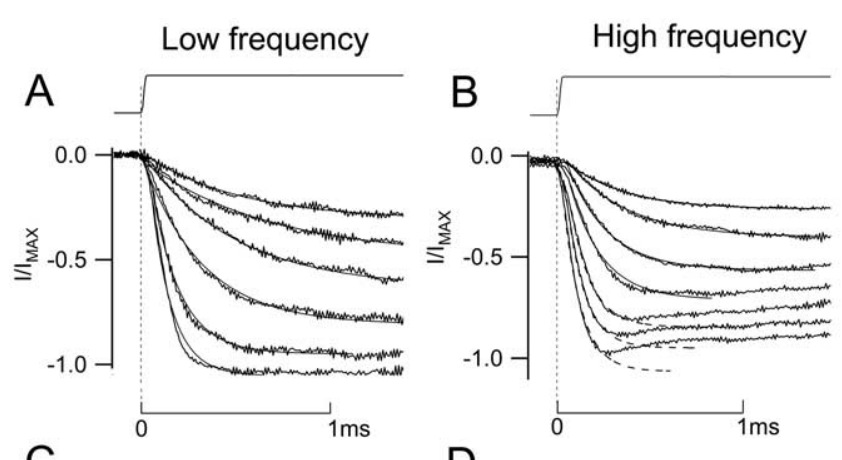

C

D
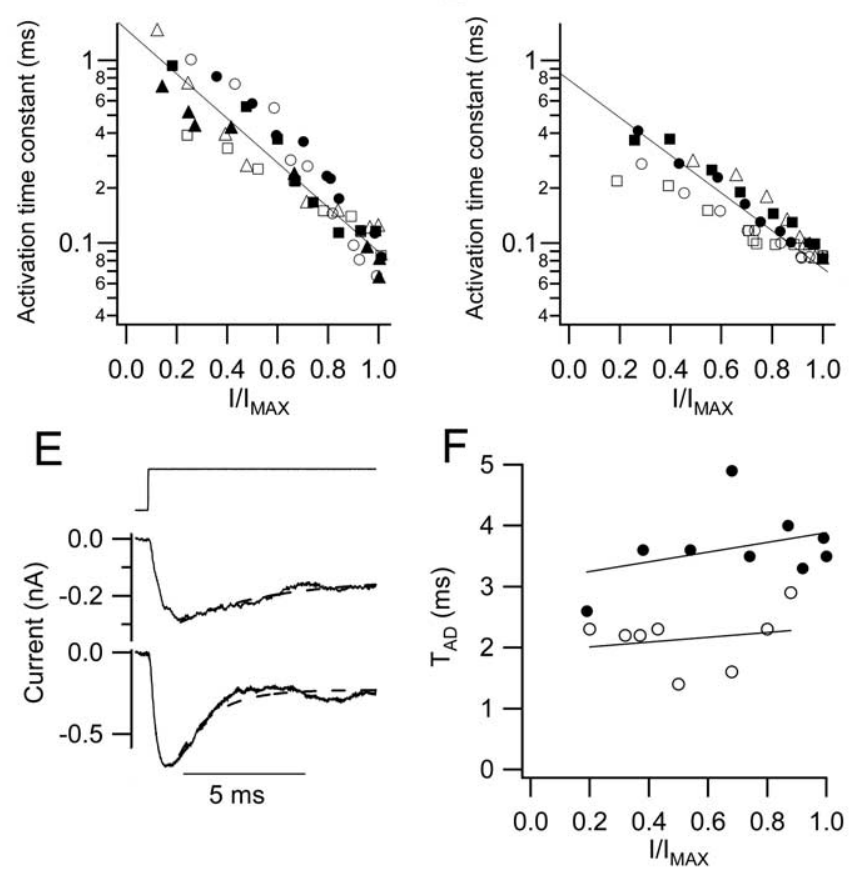

Figure 5. Tonotopic differences in the time constant of channel activation in the turtle. $\boldsymbol{A}$, Onsets of MET currents in a low-frequency hair cell $(d=0.25)$ in $0.05 \mathrm{~mm} \mathrm{Ca}^{2+}$, fitted with single exponentials. $d$ is the recording site expressed as a fractional distance along the basilar membrane from the low-frequency end. Time course of bundle displacement is shown at the top. $I_{\max }=0.75 \mathrm{nA}$. $\boldsymbol{B}$, Onsets of MET currents in a high-frequency hair cell $(d=0.63)$ in 0.05 $\mathrm{mm} \mathrm{Ca}{ }^{2+}$ fitted with single exponentials. Best fits were obtained to the rising phase, avoiding the later section with adaptation that can be seen in some of the responses. $I_{\max }=1.12 \mathrm{nA}$. C, Collected results of onset time constants plotted against fractional current activated in six lowfrequency hair cells (mean location \pm SD, $0.29 \pm 0.04$ ). $D$, Collected results of onset time constants plotted against fractional current activated in five high-frequency hair cells (mean location \pm SD, $0.66 \pm 0.04$ ). The different symbols in $\boldsymbol{C}$ and $\boldsymbol{D}$ denote different cells. Note that the lines drawn through the sets of points extrapolate back to intercept the ordinate at $\sim 1.6 \mathrm{~ms}$ in Cand $0.7 \mathrm{~ms}$ in D.E, MET current onsets showing adaptation in a low-frequency hair cell (top) and high-frequency hair cell (bottom). The dashed lines indicate single-exponential fits for fast adaptation. $\boldsymbol{F}$, Plots of the fast-adaptation time constant versus fractional current activated $\left(I / I_{\max }\right)$ for the two hair cells in $\boldsymbol{E}$. The ranges of fast-adaptation time constants were $2.7-4.6 \mathrm{~ms}$ in the six low-frequency cells and 1.4-2.4 ms in the five high-frequency cells.

line provides a convenient and objective measure for comparing the two sets of data, but it may have no physiological significance in indicating the limiting time constant of the channel for small stimuli.) The mean intercept for six low-frequency cells in $2.8 \mathrm{~mm}$ $\mathrm{Ca}^{2+}$ was $0.42 \pm 0.15 \mathrm{~ms}$ and in $0.05 \mathrm{mM} \mathrm{Ca}^{2+}$ was $1.56 \pm 0.6 \mathrm{~ms}$. In five high-frequency cells, the mean intercept in $0.05 \mathrm{mM} \mathrm{Ca}^{2+}$ was $0.71 \pm 0.17 \mathrm{~ms}$. The difference between the intercepts in 0.05 $\mathrm{mM} \mathrm{Ca}^{2+}$ at the two positions is significant on an ANOVA test at better than $p<0.01$. The time constant of fast adaptation, in contrast to activation, was independent of stimulus level (Fig.
Table 1. Kinetic properties of MET currents in the turtle auditory hair cells

\begin{tabular}{lrlllll}
\hline $\begin{array}{l}\text { Cochlear } \\
\text { location }\end{array}$ & $\begin{array}{l}\text { CF } \\
(\mathrm{Hz})\end{array}$ & $\begin{array}{l}\tau_{\text {act }} \\
(\mathrm{ms})\end{array}$ & $\begin{array}{l}F_{\mathrm{LP}} 1 / 2 \pi \tau_{\text {act }} \\
(\mathrm{Hz})\end{array}$ & $\begin{array}{l}\tau_{\text {ad }} \\
(\mathrm{ms})\end{array}$ & $\begin{array}{l}F_{\mathrm{HP}} 1 / 2 \pi \tau_{\text {ad }} \\
(\mathrm{Hz})\end{array}$ & $n$ \\
\hline $0.29 \pm 0.05$ & 90 & $0.75 \pm 0.30$ & 212 & $3.6 \pm 0.3$ & 44 & 6 \\
$0.66 \pm 0.05$ & 240 & $0.38 \pm 0.08$ & 420 & $2.0 \pm 0.2$ & 80 & 5 \\
\hline
\end{tabular}

Time constants of activation and adaptation of MET currents determined at an open probability of 0.28 . All measurements were made in a $\mathrm{Ca}^{2+}$ concentration $(0.05 \mathrm{~mm})$ similar to turtle endolymph. Cochlear location is given as the fractional distance along the cochlea from the low-frequency end. $n$ is the number of cells averaged.

$5 F$ ), as reported previously (Wu et al., 1999), although the stimulus duration was too brief to determine accurately the slowadaptation time constant. The mean time constant of fast adaptation was $3.6 \pm 0.3 \mathrm{~ms}$ averaged over the six low-frequency cells and $2.0 \pm 0.2 \mathrm{~ms}$ for the five high-frequency cells.

The parallel variation in the time constant of activation and adaptation time with hair cell characteristic frequency (CF) raises the possibility that these parameters have significance for operation of the cells in the intact cochlea. However, to make an appropriate comparison, the measurements should be made under the physiological conditions that exist in vivo. The low $\mathrm{Ca}^{2+}$ concentration $(0.05 \mathrm{~mm})$ is approximately that in the endolymph of the intact turtle cochlea (Crawford et al., 1991). Furthermore, because the activation time constant depends on stimulus level, the time constants were interpolated for an open probability of 0.28 . This open probability has been estimated as that occurring with an endolymph-like $\mathrm{Ca}^{2+}$ bathing the hair bundle (Ricci et al., 1998). The average time constants derived in this way for the two frequency locations are given in Table 1. The activation time constant $\tau_{\text {act }}$ will behave like a first-order low-pass filter with a half-power frequency $F_{\mathrm{LP}}$ equal to $\left(2 \pi \tau_{\text {act }}\right)^{-1}$. Because fast adaptation at low levels is described by a single time constant, $\tau_{\mathrm{ad}}$, it will perform like a first-order high-pass filter of half-power frequency $F_{\mathrm{HP}}$ equal to $\left(2 \pi \tau_{\mathrm{ad}}\right)^{-1}$. These half-power frequencies lie either side of the hair cell CF (Table 1), and the two kinetic processes associated with mechanotransduction together generate a bandpass filter. The center frequency of this bandpass filter can be calculated as the mean of the half-power frequencies of the lowpass and high-pass components $\left[\left(F_{\mathrm{LP}}+F_{\mathrm{HP}}\right) / 2\right]$. Using the value in Table 1, the center frequency of this bandpass filter is $128 \mathrm{~Hz}$ for hair cells with an average CF of $90 \mathrm{~Hz}$ and $250 \mathrm{~Hz}$ for cells with an average CF of $240 \mathrm{~Hz}$. The close agreement between the two frequencies in each pair strongly suggests that filtering imposed by the MET channels is a fundamental part of signal processing in turtle hair cells.

Activation and adaptation of MET channels in the rat cochlea If the MET channel kinetics in the turtle is correlated with CF of the hair cell, it might be expected that cells responsive to a quite different range of sound frequencies should have markedly different channel kinetics. This prediction can be tested by making equivalent measurements in the mammalian cochlea, where the CFs are much higher than in the turtle. Recordings from outer hair cells in neonatal rats have demonstrated recently fast adaptation similar to that seen in the turtle (Kennedy et al., 2003). MET currents in response to hair bundle deflections display similar phenomena to those in the turtle, including a rapid onset and fast adaptation (Fig. 6). Interestingly, however, there is an apparent absence of slow relaxations in the current indicative of slow adaptation: thus, the MET currents in rat outer hair cells resemble those in which only one phase of adaptation is present [Wu et al. (1999), their Fig. 7]. In addition, the time scale of events in the rat is compressed compared with the turtle, with the rise time of the current taking no more than $100 \mu$ s and adaptation occurring 
A

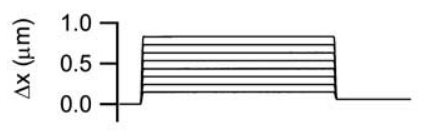

B
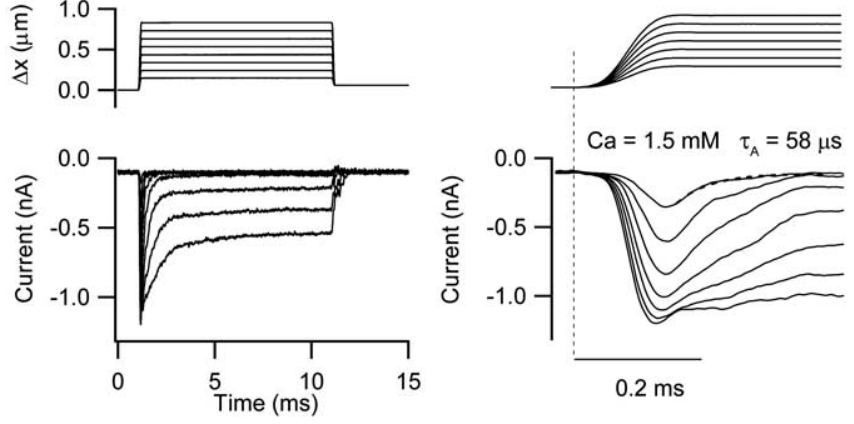

Figure 6. MET currents of a rat cochlear outer hair cell. $\boldsymbol{A}$, Average MET currents to a set of hair bundle displacements shown above. A high-frequency hair cell from the middle turn, with a holding potential of $-84 \mathrm{mV}$ in $1.5 \mathrm{~mm}$ extracellular $\mathrm{Ca}^{2+}$, is shown. Note the fast adaptation, which for the smallest responses is almost $100 \% . \boldsymbol{B}$, Initial $0.5 \mathrm{~ms}$ of response demonstrating the speed with which the current develops and adapts. The adaptive decline in the current for the smallest response has been fitted with a single exponential (dashed line) with a time constant $\left(\tau_{A}\right)$ of $58 \mu$ s, but the time course of the current onset is indistinguishable from that of the stimulus (above).

with a time constant of $58 \mu$ s for the smallest mechanical stimuli in Figure 6. For most of the cells studied in $1.5 \mathrm{mM} \mathrm{Ca}^{2+}$, the current developed with a time constant of $<50 \mu$ s, which was probably limited by the time course of the displacement step. None of the rat recordings (Figs. 6, 7) showed evidence for a decrease in the onset time constant with stimulus amplitude as seen in the turtle. This is consistent with the rise time of the stimulator being the rate-limiting step. A similar conclusion about MET channels in mammals was reached from the spectral composition of current noise (van Netten et al., 2003). These latter measurements showed that the half-power frequency attributable to the channel kinetics exceeded the $2.5 \mathrm{kHz}$ frequency of the recording filter.

Lowering extracellular $\mathrm{Ca}^{2+}$ has effects on MET currents in rat outer hair cells identical to those seen in turtle hair cells. These effects include an increase in the magnitude of the current, attributable to relief of channel block by $\mathrm{Ca}^{2+}$, and a slowing of adaptation (Kennedy et al., 2003). An additional similarity between turtle and rat hair cells is that the MET channel properties were found to vary tonotopically (Fig. 7). Recordings were made at two locations with fractional distances along the basilar membrane from the apex of 0.2 and 0.5. The CFs at these locations are 4 and $14 \mathrm{kHz}$, respectively (Müller, 1991). Recordings from five outer cells at each position showed that the peak MET current was approximately twice as large and the adaptation time constant was twice as fast at the high-frequency compared with the lowfrequency location (Fig. 7A). The maximum MET currents in high $\mathrm{Ca}^{2+}$ for the two positions were $1.36 \pm 0.12 \mathrm{nA}$ (high CF) compared with $0.78 \pm 0.13 \mathrm{nA}$ (low CF). The corresponding values for the adaptation time constant were $45 \pm 6 \mu$ s (high CF) and $83 \pm 8 \mu$ s (low $\mathrm{CF}$ ). These time constants are very fast, especially those at the high-frequency location, where they are similar to the speed of the stimulus. It is possible, therefore, that the kinetic difference between the two positions was underestimated. The value for the low CF is faster than reported previously for the same position (154 $\pm 31 \mu$ s) (Kennedy et al., 2003), which may be at least partly attributable to a faster recording time constant in the present experiments. When the extracellular $\mathrm{Ca}^{2+}$ was reduced to $0.02 \mathrm{~mm}$, the concentration in rat endolymph (Bosher and Warren, 1978), the peak current increased by $\sim 50 \%$ at each position, and the adaptation time constant became slower

\section{Low frequency $(d=0.2) \quad$ High frequency $(d=0.5)$}

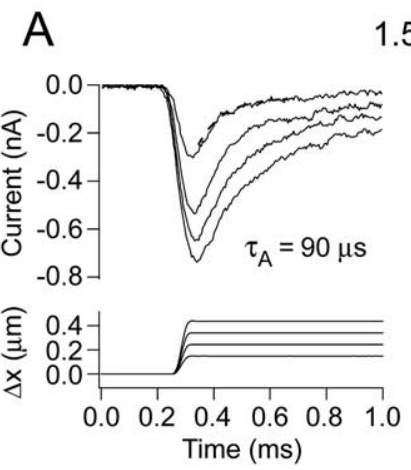

$1.5 \mathrm{mM} \mathrm{Ca}$

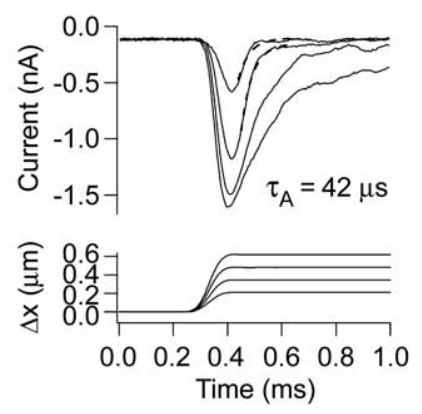

B

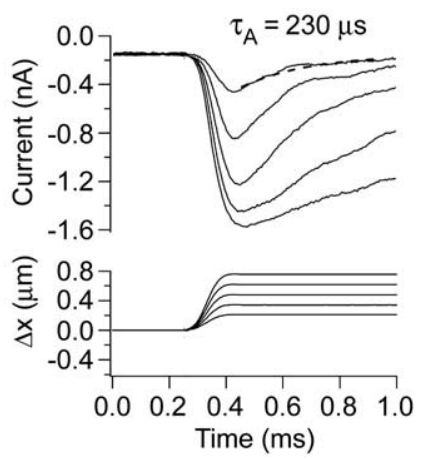

$0.02 \mathrm{mM} \mathrm{Ca}$

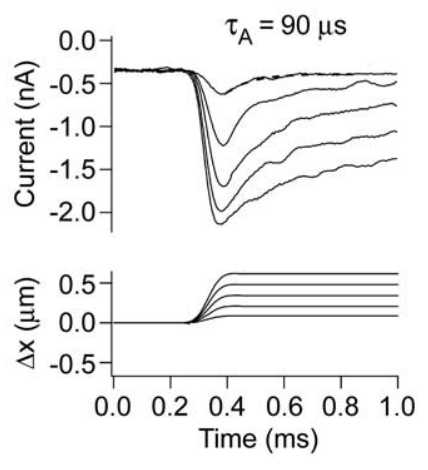

Figure 7. MET channel adaptation varies with $\mathrm{Ca}^{2+}$ and cochlear location. $A$, MET current onsets in two outer hair cells from low-frequency and high-frequency locations, denoted by $d$, fractional distance along the basilar membrane from the low-frequency end. Extracellular $\mathrm{Ca}^{2+}$ is $1.5 \mathrm{~mm}$; holding potential is $-84 \mathrm{mV}$. B, Onsets of MET currents in two other outer hair cells from the same low-frequency and high-frequency locations as in $\boldsymbol{A}$. Extracellular $\mathrm{Ca}^{2+}$ is $0.02 \mathrm{~mm}$; holding potential is $-84 \mathrm{mV}$. In both $\boldsymbol{A}$ and $\boldsymbol{B}$, the adaptive decline in the MET current has been fitted with single exponential for the small responses, and values of the time constant for fits are given next to traces. The time course of hair bundle displacements in each case is shown below the average MET currents. $\tau_{A^{\prime}}$ Adaptation time constant.

(low CF, $270 \pm 40 \mu \mathrm{s}, n=3$; high CF, $90 \mu \mathrm{s}$ ). Nevertheless, the differences in maximum current and adaptation between the two positions were retained.

Because the recordings were made on immature hair cells (P7-P10) before the onset of hearing at around P12, it might be argued that the differences between the two frequency locations reflect developmental gradients. Because at each stage of maturation, hair cells at basal locations are more advanced than those at the apex (Pujol et al., 1998), changes in either of the parameters with development could explain the apparent tonotopic differences. However, at least for the apex, we had no evidence for developmental changes in either the maximum MET current or the adaptation time constant between P5 and P18 (Kennedy et al., 2003). A tonotopic gradient in the magnitude of the MET current has also been observed in recordings from outer hair cells in an adult gerbil hemicochlea (He et al., 2004). However, no evidence was available from that work about tonotopic variations in the adaptation time constant.

\section{Discussion}

Tonotopic variations in MET channel kinetics

By fitting the onsets of MET currents in response to rapid deflections of the hair bundle, we have shown that the activation kinetics of MET channels in turtle auditory hair cells increases with stimulus level and extracellular $\mathrm{Ca}^{2+}$. A speeding up of the time 
constant with level is expected for a channel system in which the opening rate constant is displacement sensitive (Corey and Hudspeth 1983; Crawford et al., 1989), and it does not explicitly require the involvement of $\mathrm{Ca}^{2+}$. However, our results also indicate that $\mathrm{Ca}^{2+}$ accelerates channel opening. In addition to their displacement and calcium sensitivity, the channel kinetics also varied with the CF of the cell, agreeing with previous results on the spectral composition of current fluctuations in turtle hair cells (Ricci, 2002). In the latter work, the equivalent time constants derived from the half-power frequencies of spectra in low (0.25 mm) $\mathrm{Ca}^{2+}$ were $0.55 \mathrm{~ms}$ (low CF) and $0.21 \mathrm{~ms}$ (high CF). These values are slightly faster than those reported here (low CF, $0.75 \mathrm{~ms}$; high CF, $0.38 \mathrm{~ms}$ ) (Table 1), but this might be expected because the $\mathrm{Ca}^{2+}$ concentration here was lower $(0.05 \mathrm{~mm})$. We have previously reported similar $\mathrm{Ca}^{2+}$ and CF dependence of the fast-adaptation time constant (Ricci and Fettiplace, 1997; Ricci et al., 1998), properties we attributed to differences in single METchannel conductance (Ricci et al., 2003). Thus, MET channels in turtle hair cells with high CF have larger unitary conductance, permitting greater $\mathrm{Ca}^{2+}$ influx to drive adaptation faster. This simple hypothesis may also apply to the differences in activation kinetics: larger $\mathrm{Ca}^{2+}$ influx in cells with higher CF facilitates MET channel opening. The effect of increasing cytoplasmic calcium buffering to slow the kinetics implies an intracellular action of $\mathrm{Ca}^{2+}$. However, the lack of effect of membrane potential on the activation kinetics is different from its effects on fast adaptation, in which depolarization to $+80 \mathrm{mV}$ abolishes adaptation in turtle hair cells (Crawford et al. 1989; Ricci et al. 2000) and suggests a separate site of action for $\mathrm{Ca}^{2+}$.

There are several ways of reconciling these results. One is that both channel activation and adaptation are controlled from an intracellular site, but the site is more sensitive to $\mathrm{Ca}^{2+}$ for activation than adaptation. So if there is some residual $\mathrm{Ca}^{2+}$ influx at $+80 \mathrm{mV}$ (a membrane potential negative to the $\mathrm{Ca}^{2+}$ equilibrium potential), it could still support activation. Depolarization to $+80 \mathrm{mV}$ differed in one important respect from experiments in which extracellular $\mathrm{Ca}^{2+}$ was lowered or intracellular calcium buffer was raised. The depolarizing voltage pulse was brief (only $20 \mathrm{~ms}$ of each $100 \mathrm{~ms}$ repetition), and it may therefore have caused a smaller maintained reduction in stereociliary $\mathrm{Ca}^{2+}$. Another hypothesis is that there are both intracellular and extracellular actions of $\mathrm{Ca}^{2+}$ and that changing the buffer affects the internal site, whereas changing external $\mathrm{Ca}^{2+}$ affects both sites. Both hypotheses imply that $\mathrm{Ca}^{2+}$ has multiple effects on the MET channels. A component of the MET channel in vertebrate hair cells has been identified recently as TRPA1, a member of the transient receptor potential (TRP) superfamily (Corey et al., 2004). Twin facilitatory and inhibitory effects of $\mathrm{Ca}^{2+}$ have been reported on TRP channels, including the founder TRP channel in Drosophila photoreceptors (Hardie, 1995).

\section{The mammalian MET channel}

Similar control principles may apply to the mammalian MET channel. Although it was not possible to measure the activation time constant with the existing techniques, the adaptation time constant depended on external $\mathrm{Ca}^{2+}$ and cochlear location in a similar manner to the turtle. However, the time constants were over 10-fold faster in the rat, which may explain the inability to measure the onset time constant with the existing methods. If the same sixfold difference between adaptation and activation time constants holds for the mammal as for the turtle, then for small stimuli, the activation time constants (in $0.02 \mathrm{~mm} \mathrm{Ca}^{2+}$ at room temperature) are predicted to be $15-45 \mu \mathrm{s}$, below the resolution of our stimulation and recording systems. It seems implausible that the properties of mammalian MET channels are an extension of those in the turtle produced by a further increase in channel conductance. Single-channel events have been observed in outer hair cells and have a conductance of 100 pS (Géléoc et al., 1997), no larger than the unitary conductance in the turtle (Ricci et al., 2003).

What other factors might be responsible for the faster kinetics in the mammal with little difference in maximum current magnitude? One possibility is that MET channels in mammalian cochlear hair cells contain a different set of $\alpha$ subunit isoforms from those used in the turtle or that the properties are modified by another accessory $\beta$ subunit. The local environment for the channel may also differ: membrane lipids such as phosphatidylinositol 4,5-bisphosphate can alter the time course of adaptation (Hirono et al. 2004) so may also affect activation. A third possibility is that the mechanical coupling to the channel, for example the gating springs, may differ in some way. The contrast between mammal and reptile becomes even more pronounced if the parameters are adjusted for the conditions prevailing in vivo. We previously used an eightfold reduction in adaptation time constant to correct for the higher temperature, the endolymphatic potential, and elevated endolymphatic $\mathrm{K}^{+}$in vivo (Kennedy et al., 2003). Applying this scaling factor (assuming no other steps in the pathway become rate limiting) to the adaptation time constants measured in $0.02 \mathrm{mM} \mathrm{Ca}^{2+}$ gives values of 34 and $11 \mu \mathrm{s}$ for the low- and high-frequency locations, respectively. These time constants $\left(\tau_{\mathrm{ad}}\right)$ may be converted to half-power frequencies $\left(F_{\mathrm{HP}}=\right.$ $\left.1 / 2 \pi \tau_{\mathrm{ad}}\right)$ of 4.7 and $14.5 \mathrm{kHz}$, which are very similar to the CFs of the respective cochlear locations. The close agreement between the $\mathrm{CF}$ and the corner frequency attributable to the adaptation time constant may be somewhat fortuitous given the uncertainty in the corrections. Nevertheless, it reinforces the notion of a relationship between hair cell CF and MET channel kinetics.

\section{A bandpass transduction channel filter}

What is the function of the filtering imposed by transduction? Because this filter is a combination of a first-order high-pass and a first-order low-pass filter, the roll off at both low and high frequencies is relatively shallow compared with the major frequency-selective filter, which in the turtle is contributed by electrical tuning of the receptor potential (Crawford and Fettiplace, 1981). This is illustrated in Figure 8 for the two locations examined in the turtle cochlea. The hair cell tuning at each position was calculated as a parallel resonance (Crawford and Fettiplace, 1981) with resonant frequencies of 90 and $240 \mathrm{~Hz}$ with quality factors, $Q_{3 \mathrm{~dB}}$, of 3 and 8 respectively, values within the range of those observed experimentally. The relative frequency selectivity contributed by the transduction filter, the product of the low-pass and high-pass components, was calculated from the results in Table 1. In both cases, the transduction filter is centered on the electrical resonance. For the turtle, transduction will act as a "prefilter" so that excess noise in transduction is not injected into and amplified by the electrical resonator. The relatively broad tuning of this transduction filter may be advantageous in enabling its center frequency to be approximately matched to that of the much more sharply tuned electrical resonance.

An alternative role for the transduction filter is to band limit the noise in transduction, thereby improving the signal-to-noise ratio in the MET current. Traditionally, noise has been thought to degrade signal reception, although recent evidence suggests that, in frog hair cells, small amounts of added noise may actually improve sensitivity by stochastic resonance (Jaramillo and 

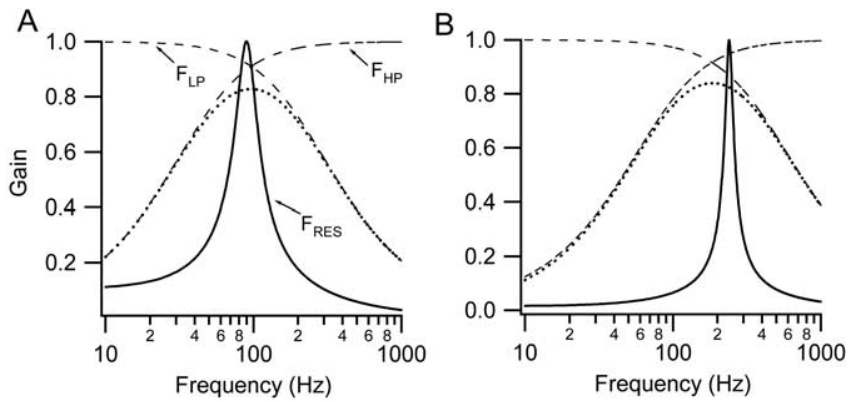

Figure 8. Comparison of transduction filter and hair cell resonance. $A$, Low-frequency position. $F_{\text {RES }}$ is the tuning endowed by the electrical resonance calculated for a resonant frequency, $F_{0}$, of $90 \mathrm{~Hz}$ and a quality factor, $Q$, of $3 . Q$ is the resonant frequency divided by the $3 \mathrm{~dB}$ bandwidth of the tuning curve. The relationship between $F_{\text {RES }}$ and frequency $(F)$ is given by the following: $F_{\mathrm{RES}}=\left[\left(Q^{2}+F_{0}{ }^{2} / F^{2}\right) /\left(1+Q^{2} \times\left(F_{0} / F-F / F_{0}\right)^{2}\right]^{0.5}\right.$. The high-pass filter $F_{\mathrm{HP}}$ and low-pass filter $F_{\mathrm{LP}}$ were calculated as first-order filters with half-power frequencies of 44 and $212 \mathrm{~Hz}$ derived form the activation and adaptation time constants (Table 1). $\boldsymbol{B}$, High-frequency position. The electrical resonance was calculated for a resonant frequency of $240 \mathrm{~Hz}$ and a quality factor, $Q_{3 \mathrm{~dB}}$ of 8 . The high-pass filter $F_{\mathrm{HP}}$ and low-pass filter $F_{\mathrm{LP}}$ were calculated as first-order filters with half-power frequencies of 80 and $420 \mathrm{~Hz}$ derived from the activation and adaptation time constants (Table 1). In $\boldsymbol{A}$ and $\boldsymbol{B}$, the transduction filter (the product of $F_{\mathrm{HP}}$ and $\left.F_{\mathrm{LP}}\right)$ is drawn as the dotted line.

Wiesenfeld, 1998). At least four noise sources can be identified in hair-cell transduction. These are in the stimulus or hair bundle motion (Crawford and Fettiplace, 1985; Denk and Webb, 1992), including the contribution from adaptation motors (Frank et al., 2002); thermal motion in the gating springs (van Netten et al., 2003), proposed to deliver force to the channel (Howard and Hudspeth, 1988); and the stochastic behavior of the MET channels (Holton and Hudspeth, 1986; Ricci, 2002). These noise components can be expressed as an equivalent root mean square displacement of the hair bundle, each amounting to several nanometers (van Netten et al., 2003). The noise amplitude is significant when compared with movements that may occur at auditory threshold, which may be $<1 \mathrm{~nm}$, only $1 / 10$ the noise level. When driven by sound, deflection of the tip of the hair bundle is comparable to displacement of the basilar membrane (Hu et al., 1999), which in the turtle has a peak amplitude of $\sim 0.3 \mathrm{~nm}$ at auditory threshold (Crawford and Fettiplace, 1983). We suggest that $\mathrm{Ca}^{2+}$-dependent activation and adaptation, by narrowing the bandwidth of the detector, provides a mechanism for noise reduction, especially the broad-band thermal noise in the stimulus and gating springs. These effects do not preclude other roles for fast adaptation, including the mechanical amplification of the stimulus by active bundle motion (Hudspeth, 1997; Fettiplace et al., 2001; Kennedy et al., 2005). However, it will be important in future experiments to determine the limits set by the channel gating kinetics. Given the extraordinary speed of the mammalian hair-cell channels, much faster than other voltage- or ligandgated ion channels (Hille, 2001), it will require substantial improvements in the stimulation and recording techniques to establish their frequency response.

\section{References}

Bosher SK, Warren RL (1978) Very low calcium content of cochlear endolymph, an extracellular fluid. Nature 273:377-378.

Corey DP, Hudspeth AJ (1979) Response latency of vertebrate hair cells. Biophys J 26:499-506.

Corey DP, Hudspeth AJ (1983) Kinetics of the receptor current in bullfrog saccular hair cells. J Neurosci 3:962-976.

Corey DP, Garcia-Anoveros J, Holt JR, Kwan KY, Lin SY, Vollrath MA, Amalfitano A, Cheung EL, Derfler BH, Duggan A, Geleoc GS, Gray PA, Hoffman MP, Rehm HL, Tamasauskas D, Zhang DS (2004) TRPA1 is a candidate for the mechanosensitive transduction channel of vertebrate hair cells. Nature 432:723-730.

Crawford AC, Fettiplace R (1981) An electrical tuning mechanism in turtle cochlear hair cells. J Physiol (Lond) 312:377-412.

Crawford AC, Fettiplace R (1983) Auditory nerve responses to imposed displacements of the turtle basilar membrane. Hear Res 12:199-208.

Crawford AC, Fettiplace R (1985) The mechanical properties of ciliary bundles of turtle cochlear hair cells. J Physiol (Lond) 364:359-379.

Crawford AC, Evans MG, Fettiplace R (1989) Activation and adaptation of transducer currents in turtle hair cells. J Physiol (Lond) 419:405-434.

Crawford AC, Evans MG, Fettiplace R (1991) The actions of calcium on the mechanoelectrical transducer currents of turtle hair cells. J Physiol (Lond) 434:369-398.

Denk W, Webb WW (1992) Forward and reverse transduction at the limit of sensitivity studied by correlating electrical and mechanical fluctuations in frog saccular hair cells. Hear Res 60:89-102.

Eatock RA (2000) Adaptation in hair cells. Annu Rev Neurosci 23:285-314.

Fettiplace R (2004) Transduction channels in hair cells. In: Transduction channels in sensory cells (Frings DS, Bradley J, eds), pp 31-56. Weinheim, Germany: Wiley-VCH.

Fettiplace R, Ricci AJ (2003) Adaptation in auditory hair cells. Curr Opin Neurobiol 13:446-451.

Fettiplace R, Ricci AJ, Hackney CM (2001) Clues to the cochlear amplifier from the turtle ear. Trends Neurosci 24:169-175.

Frank JE, Markin V, Jaramillo F (2002) Characterization of adaptation motors in saccular hair cells by fluctuation analysis. Biophys J 83:3188-3201.

Géléoc GS, Lennan GW, Richardson GP, Kros CJ (1997) A quantitative comparison of mechanoelectrical transduction in vestibular and auditory hair cells of neonatal mice. Proc R Soc Lond B Biol Sci 264:611-621.

Hardie RC (1995) Photolysis of caged $\mathrm{Ca}^{2+}$ facilitates and inactivates but does not directly excite light-sensitive channels in Drosophila photoreceptors. J Neurosci 15:889-902.

He DZ, Jia S, Dallos P (2004) Mechanoelectrical transduction of adult outer hair cells studied in a gerbil hemicochlea. Nature 429:766-770.

Hille B (2001) Ion channels of excitable membranes, Chap 18, pp 572-602. Sunderland, MA: Sinauer.

Hirono M, Denis CS, Richardson GP, Gillespie PG (2004) Hair cells require phosphatidylinositol 4,5-bisphosphate for mechanical transduction and adaptation. Neuron 44:309-320.

Hodgkin AL, Huxley AF (1952) A quantitative description of membrane current and its application to conduction and excitation in nerve. J Physiol (Lond) 117:500-544.

Holton T, Hudspeth AJ (1986) The transduction channel of hair cells from the bull-frog characterized by noise analysis. J Physiol (Lond) 375:195-227.

Howard J, Hudspeth AJ (1988) Compliance of the hair bundle associated with gating of mechanoelectrical transduction channels in the bullfrog's saccular hair cell. Neuron 1:189-199.

Hu X, Evans BN, Dallos P (1999) Direct visualization of organ of Corti kinematics in a hemicochlea. J Neurophysiol 82:2798-2807.

Hudspeth A (1997) Mechanical amplification of stimuli by hair cells. Curr Opin Neurobiol 7:480-486.

Hudspeth AJ (1989) How the ear's works work. Nature 341:397-404.

Jaramillo F, Wiesenfeld K (1998) Mechanoelectrical transduction assisted by Brownian motion: a role for noise in the auditory system. Nat Neurosci 1:384-388.

Kennedy HJ, Evans MG, Crawford AC, Fettiplace R (2003) Fast adaptation of mechanoelectrical transducer channels in mammalian cochlear hair cells. Nat Neurosci 6:832-6836.

Kennedy HJ, Crawford AC, Fettiplace R (2005) Force generation by mammalian hair bundles supports a role in cochlear amplification. Nature 433:880-883.

Müller M (1991) Frequency representation in the rat cochlea. Hear Res $51: 247-254$.

Ohmori H (1985) Mechanotransduction currents in isolated vestibular hair cells of the chick. J Physiol (Lond) 359:189-217.

Pujol R, Lavigne-Rebillard M, Lenoir M (1998) Development of sensory and neural structures in the mammalian cochlea. In: Development of the auditory system (Rubel EW, Popper AN, Fay RR, eds), pp 146-192. New York: Springer. 
Ricci A (2002) Differences in mechano-transducer channel kinetics underlie tonotopic distribution of fast adaptation in auditory hair cells. J Neurophysiol 87:1738-1748.

Ricci AJ, Fettiplace R (1997) The effects of calcium buffering and cyclic AMP on mechano-electrical transduction in turtle auditory hair cells. J Physiol (Lond) 501:111-124.

Ricci AJ, Fettiplace R (1998) Calcium permeation of the turtle hair cell mechanotransducer channel and its relation to the composition of endolymph. J Physiol (Lond) 506:159-173.

Ricci AJ, Wu Y-C, Fettiplace R (1998) The endogenous calcium buffer and the time course of transducer adaptation in auditory hair cells. J Neurosci 18:8261-8277.

Ricci AJ, Crawford AC, Fettiplace R (2000) Active hair bundle motion linked to fast transducer adaptation in auditory hair cells. J Neurosci 20:7131-7142.
Ricci AJ, Crawford AC, Fettiplace R (2003) Tonotopic variation in the conductance of the hair cell mechanotransducer channel. Neuron 40:983-990.

Tucker TR, Fettiplace R (1996) Monitoring calcium in turtle hair cells with a calcium-activated potassium channel. J Physiol (Lond) 494:613-626.

van Netten SM, Kros CJ (2000) Gating energies and forces of the mammalian hair cell transducer channel and related hair bundle mechanics. Proc R Soc Lond B Biol Sci 267:1915-1923.

van Netten SM, Dinklo T, Marcotti W, Kros CJ (2003) Channel gating forces govern accuracy of mechano-electrical transduction in hair cells. Proc Natl Acad Sci USA 100:15510-15515.

Wu Y-C, Ricci AJ, Fettiplace R (1999) Two components of transducer adaptation in auditory hair cells. J Neurophysiol 82:2171-2181. 